\section{Commit to equity for women researchers}

Heads of research agencies from nearly 50 countries - large and small, with developed and emerging economies - adopted a Statement of Principles and Actions Promoting the Equality and Status of Women in Research at the Global Research Council's fifth annual meeting last month in New Delhi (see go.nature. com/lyqtyg).

According to a report commissioned by the Science and Engineering Research Board of India and Research Councils UK, which hosted the meeting, women make up only $11 \%$ of full science and engineering professors in the European Union, less than $25 \%$ of academics in Asia and less than $5 \%$ of researchers in some Middle Eastern countries (see go.nature.com/1uywmgu). The report echoes statistics from the US National Science Foundation, of which I am director (see go.nature.com/1rpvmrk for the Science and Engineering Indicators).

At the meeting, we gained greater awareness of longstanding historical obstacles to women's participation in certain fields, and of the importance of including gender considerations in research design and outcome analysis. Each of us came away with a firmer idea of the opportunities to lead within our jurisdictions, and in a wider policy context.

The national research heads agreed to "expect and encourage improved equality and diversity policies and practices" within their respective research provinces, and recommended a list of actions. These included diversity training, recognizing unconscious bias, implementing family-friendly policies and creating pathways for women to rise to leadership positions. We agreed to collect follow-up data and make them available for comparative analysis.

Only by supporting the best talent - wherever it hails from
- can we truly encourage and support research with the greatest academic, economic and societal impacts. Ensuring global equity for women in research requires that we each make a personal commitment to action.

France A. Córdova National Science Foundation, USA. acollins@nsf.gov

\section{Don't bank African rhinos in Australia}

The Australian Rhino Project (see go.nature.com/28c8s29) aims to move 80 rhinoceroses from South Africa to Australia by 2019 as conservation 'insurance' against the poaching epidemic - at a cost of about US $\$ 3.5$ million. The first 6 will go this year. In our view, this project is diverting funds and public interest away from the actions necessary to conserve the animals in Africa.

The scheme is supported by the South African and Australian governments, academic institutions in Australia, and corporations and conservationmanagement organizations. Its cost equates to more than the anti-poaching budget of South African National Parks for 2015. We suggest that this money would be better spent on local, on-theground action in South Africa or on education programmes in Asia to reduce demand for rhino horn.

Africa's rhinos are not even the highest priority in pachyderm conservation, particularly because only white rhinos from private collections are to be moved. The global estimated populations of white and black rhinos are 20,170 and 4,880, respectively - still further from extinction than Indian (2,575), Sumatran (275) and Javan (60) rhinos.

We feel that the project has echoes of colonial times, when African resources were exploited. Taking biodiversity assets such as rhinos for 'safe keeping' in the West seems to us as patronizing and disempowering as the theft of cultural artefacts.
Matt W. Hayward ${ }^{\star}$ Bangor

University, UK.

m.hayward@bangor.ac.uk

${ }^{*}$ On behalf of 4 correspondents (see go.nature.com/1w32n9qfor full list).

\section{Freelance scientists need EU for support}

As 'freelance' scientists, we undertake research jointly with academic institutions and provide Earth-science modelling services for clients an alternative career path that European Union funding enables us to pursue. If the United Kingdom chooses to leave the EU after this week's referendum, small private research organizations and independent researchers could be doomed.

Independent researchers cannot apply for funding from UK research councils. Private research organizations need demonstrable in-house research capacity and a minimum of ten researchers. These eligibility criteria are at odds with those of the UK arts councils and the European Commission, which consider proposals from anyone with a track record in their discipline.

With $88 \%$ of UK postdocs never securing a tenured position (The Scientific Century: Securing our Future Prosperity;

Royal Society, 2010), these requirements need to be relaxed (see also Nature 520, 144-147; 2015). Entrepreneurial young scientists could then continue their research without the backing of a university.

For the United Kingdom to maintain its competitive edge, funding bodies need to recognize that the research landscape is changing. In this era of digital connectivity, scientists can still be embedded in the research community while working outside traditional research organizations.

Cécile B. Ménard, Melody Sandells CORES Science and Engineering, Burnopfield, Newcastle upon Tyne, UK. cecile.menard@coresscience.co.uk

\section{Carry on celebrating Mendel's legacy}

I disagree with Gregory Radick's strategy for teaching modern genetics (Nature 533, 293; 2016). In my view, we should not discard the legacies of Gregor Mendel, William Bateson, Walter Sutton, Thomas Hunt Morgan and their ilk, whose beautiful science continues to provide the best explanations for inheritance.

I teach basic genetics to veterinary students, who learn the laws of inheritance without any historical context, and to biology students, who learn the scientific method and how it influenced the development of genetic concepts. The biologists revisit hypotheses proposed to account for the same observations - such as Bateson's and W.F. R. Weldon's contrasting views of inheritance. They come to understand that Mendel's hypothesis of hereditary units ('alleles') explains the data better. They learn that theories and hypotheses are not immutable, that science is incomplete, and that every discovery stimulates new questions.

With the Boveri-Sutton chromosome theory, it became clear that Mendelian inheritance is indeed the core of genetics. It underpins association-mapping studies, population genetics and clinical genetics. Such new information continues to corroborate Mendel's hypothesis of inheritance. There is no need to remove Mendel from his honorary position in the genetics curriculum to spark creative science.

Tatiana T. Torres Institute of Biosciences, University of São Paulo, Brazil. tttorres@ib.usp.br

CONTRIBUTIONS Correspondence may be sent to correspondence@ nature.com after consulting go.nature.com/cmchno 